\title{
El testamento en los códigos de estatuto personal de los países árabes*
}

\section{The testament in the codes of personal status in Arab countries}

\author{
Caridad RUIZ-ALMODÓVAR \\ Universidad de Granada \\ caridad@ugr.es
}

Recibido: 14 de enero de 2015

Aceptado: 10 de mayo de 2015

\section{RESUMEN}

Estudio comparado del testamento en los códigos de estatuto personal de los siguientes países árabes: Argelia, Egipto, Emiratos Árabes Unidos, Iraq, Jordania, Kuwait, Marruecos, Mauritania, Omán, Qatar, Siria, Sudán, Túnez y Yemen.

Palabras clave: Derecho Privado, Testamento, Familia, Países Árabes.

\begin{abstract}
A comparative study of testament as included in the codes of personal status of the following Arab countries: Algeria, Egypt, United Arab Emirates, Iraq, Jordan, Kuwait, Morocco, Mauritania, Oman, Qatar, Syria, Sudan, Tunisia, and Yemen.

Keywords: Law of Personal Status, Testament, Family, Arab Countries.
\end{abstract}

Sumario: 1. Conclusión del testamento, 2. Elementos constitutivos y requisitos del testamento, 2.1. El texto, 2.2. El testador, 2.3. El legatario, 2.4. El legado.

* Realizado en el marco del Proyecto de Investigación "La primavera árabe: integración de los derechos fundamentales y las relaciones Iglesia-Estado en los procesos constituyentes de las nuevas democracias" (DER 2012-33513), financiado por el Ministerio de Economía y Competitividad. 
La reglamentación del testamento (wașiyya) en los países árabes forma parte de los Códigos de Estatuto Personal (Qānūn al-Aḥwāl al-Šajṣiyya) o Códigos de la Fami-

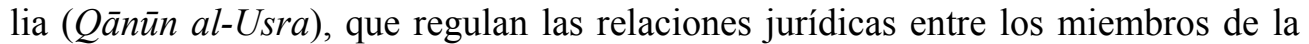
familia, es decir el matrimonio, su ruptura, filiación, sucesiones y testamentos, excepto en Egipto', que el testamento es objeto de una ley específica, así como en Bahrein, Líbano y Libia². Estos códigos que se basan en derecho islámico, bien especificando un escuela jurídica o bien remitiendo a la ley islámica, han introducido preceptos no sólo de las otras escuelas jurídicas, sino también de derecho positivo, pero además la mayoría de ellos han sido reformados y, en todos los casos, tanto la primera redacción como las posteriores modificaciones han ido encaminadas a mejorar la situación legal de las mujeres y adecuarlo algo más a la realidad social.

Todos estos códigos, excepto el tunecino ${ }^{3}$, para todo aquello que no esté regulado en el propio código remiten a: la ley islámica en el argelino ${ }^{4}(\operatorname{art} .222)$ y el yemenís ${ }^{5}$ (art. $349)$, los principios de la ley islámica más idóneos con los textos de dicho código en el iraquí (art.1/2) y el omaní (art. 281/d), primero a la escuela mālikí, luego a la hanbalí,

\footnotetext{
${ }^{1}$ Qānūn al-Wașiyya, ley 71 de 24 de junio de 1946, véase al-Mīrāt wa-l-wașiyya wa-l-wilāya 'alà alnafs wa-l-māl. El Cairo: al-Hay'a al-'Āmma li-Šu'ūn al-Mațābi‘ Amīriyya, 1998, 7ª edición, pp. 19-40, y para la traducción RUIZ-ALMODÓVAR, Caridad, El derecho privado en los paises árabes. Edición y traducción, Granada: Universidad de Granada y Fundación Euroárabe de Altos Estudios, 2005, pp. 61-75.

${ }^{2}$ Desconozco la legislación del testamento en estos tres países.

${ }^{3}$ Promulgado por el Decreto del 13 de agosto de 1956, está compuesto por 213 artículos contenidos en doce libros. Ha sido modificado en quince ocasiones por las leyes 40 de 27/12/1957; 70 de 04/07/1958; 77 de 19/06/1959; 41 de 22/10/1962 -ratificando el decreto 21 de 30/08/1962-; 01 de 21/04/1964 -ratificando el decreto ley 01 de 20/02/1964-; 17 de 18/05/1964; 49 de 03/06/ 1966; 07 de 18/02/1981; 48 de 04/05/1992; 74 de 12/07/1993; 10 de 06/03/2006; 32 de 14/05/2007; 20 de 04/03/ 2008; 39 de 26/07/2010 y 50 de 01/11/2010, vease Maŷallat al-Ahwāl al-Šajṣiyya, Túnez: Manšūāt al-Mațba'a al-Rasmiyya li-l-Ŷumhūriyya al-Tūnisiyya, 2011, pp. 53-58, y para la traducción RUIZALMODÓVAR, Caridad, El derecho privado en los países árabes, pp. 523-526.

${ }^{4}$ Promulgado por la Ley 11 del 9 de junio de 1984, está compuesto por 224 artículos contenidos en cuatro libros. Ha sido modificado en una ocasión por el decreto 05-02 del 27 de febrero de 2005, véase Qānūn al-Usra, Argel: Munšāt Būrūtīk, 1988, pp. 34-36; para la modificación al-Ŷarìda al-Rasmiyya, $\mathrm{n}^{\circ} 15$ (27-02-2005), pp. 18-22, y para la traducción RUIZ-ALMODÓVAR, Caridad, El derecho privado en los países árabes, pp. 35-36.

${ }^{5}$ Promulgado por la Ley 20 del 27 de marzo de 1992, está compuesto por 351 artículos contenidos en seis libros. Ha sido modificado en cuatro ocasiones por la Leyes 27 del 11 de noviembre de 1998; 24 del 10 de abril de 1999; 34 de 2002 y en diciembre de 2009, véase Qānūn raq (20) li-sana 1992 bi-ša'n alahwwāl al-šajșiyya wa-ta 'dīlāti-hi, s. 1.: Wazārat al-Šu'ūn wa-l-Qānūniyya, 2003, pp. 34-39, y para la traducción RUIZ-ALMODÓVAR, Caridad, El derecho privado en los países árabes, pp. 563-568.

${ }^{6}$ Promulgado por la Ley 188 del 19 de diciembre de 1959, está compuesto por 94 artículos contenidos en ocho capítulos. Ha sido modificado en dieciséis ocasiones por las leyes y decretos siguientes: Leyes 11 de 1963; 21 de 1978; 72 de 1979; 57, 156 y 189 de 1980; 125 de 1981; 34 de 1983; 51 de 1985; 5 y 65 de 1986; 90 y 107 de 1987; 62 de 1994, y los Decretos 1.128 de 1985, y 560 de 1987, además ha sido ampliado por ocho Decretos del Consejo del Mando de la Revolución: 1.708 de 1981; 147 de 1982; 807 y 1.000 de 1983; 211 de 1984; 352 y 544 de 1987, y 145 de 1988, véase Qānūn alAḥwāl al-Šașiyya wa-ta'dīlāti-hi, s.l.: s.e.,1989, $5^{\text {a }}$ edición, pp. 59-62, y para la traducción RUIZALMODÓVAR, Caridad, El derecho privado en los países árabes, pp. 93-94.
} 
šāfíí y hanafí en el emiratí ${ }^{8}$ (art. 2/3), la escuela hanafí en el jordano ${ }^{9}$ (art. 325), el sirio ${ }^{10}$ (art. 305) y el sudanés ${ }^{11}$ (art. 4), la escuela mālikí en el kuwaití1 ${ }^{12}$ (art. 343), el marroquí1 ${ }^{13}$ (art. 400) y el mauritano ${ }^{14}$ (art. 311), y la escuela hanbalí en el qatarí15 (art. 3).

El testamento es el documento por el cual una persona puede disponer para después de su fallecimiento de sus bienes, tal como definen los códigos ${ }^{16}$ de manera muy similar.

El testador únicamente puede disponer libremente mediante testamento de un tercio $^{17}$ de sus bienes, de tal modo que todo aquello que exceda dicho tercio requiere para su validez la autorización de los herederos mayores de edad. Antes de cumplir

\footnotetext{
${ }^{7}$ Promulgado por el Decreto Ley 32 del 4 de junio de 1997, está compuesto por 282 artículos contenidos en cinco libros, véase Qānūn al-Aḥwāl al-Šasìyya, s.l: Wizārat al-'Adl wa-l-Awqāf wa-l-Šu'ūn al-Islāmiyya, 1997, pp. 60-67, y para la traducción RUIZ-ALMODÓVAR, Caridad, El derecho privado en los países árabes, pp. 370-375.

${ }^{8}$ Promulgado por el Decreto Ley 28 de 2005, está compuesto por 363 artículos contenidos en cinco libros, véase Qānūn al-Ahwwāl al-Šajṣiyya. Abu Dabi: Dā'ira al-Qaḍā', 2014, pp. 111-121 y para la traducción RUIZ-ALMODÓVAR, Caridad, "El código de estatuto personal de Emiratos Árabes Unidos (II)", Miscelánea de Estudios Árabes y Hebraicos, Sección Árabe-Islam, 64 (2015), pp. 234-238.

${ }^{9}$ Promulgado por la Ley 36 del 26 de septiembre de 2010, está compuesto por 328 artículos contenidos en nueve capítulos, derogó el código promulgado en 1976 y modificado en 1977 y 2001, véase Qānūn alAḥwāl al-Šajṣiyya, Ed. al-Muhāmī Taysīr Aḥmad al-Za'abī, s.l.: Mawsū'at al-Urdun al-Qānūniyya, 2010, pp. 95-104, y para la traducción RUIZ-ALMODÓVAR, Caridad, "El nuevo código jordano de estatuto personal”, Miscelánea de Estudios Árabes y Hebraicos, Sección Árabe-Islam, 61 (2012), pp. 212-216.

${ }^{10}$ Promulgado por el Decreto Ley 59 del 17 de septiembre de 1953, está compuesto por 308 artículos contenidos en seis libros. Ha sido modificado en una ocasión por la Ley 34 del 31 de diciembre de 1975, véase Qānūn al-Aḥwāl al-Šajșiyya, s.l.: Mu'assasat al-Nūrī li-1-Ṭibā'a wa-1-Našr wa-1-Tawzī‘, 1992, pp. 67-79, y para la traducción RUIZ-ALMODÓVAR, Caridad, El derecho privado en los países árabes, pp. 415-424.

${ }^{11}$ Promulgado por la Ley 24 de julio de 1991, está compuesto por 411 artículos distribuidos en cinco libros, véase Qūnūn al-Aḥwāl al-Šajsịyya al-Sūdānī li-l-Muslimīn, http://www.justice-lawhome.com/vb/showthread.php?t=7909, (consultada 12-11-2013), arts. 286-318, y para la traducción RUIZ-ALMODÓVAR, Caridad, El derecho privado en los países árabes, pp. 476-481.

${ }^{12}$ Promulgado por la Ley 51 del 7 de julio de 1984, está compuesto por 347 artículos distribuidos en tres partes, véase Qānūn al-Ahwāl al-Šajṣiyya, s.l.: al-Fatwà wa-l-Tašrī', s.d., pp. 65-95, y para la traducción RUIZ-ALMODÓVAR, Caridad, El derecho privado en los países árabes, pp. 161-174.

${ }^{13}$ Promulgado por la Ley 7003 del 3 de febrero de 2004, está compuesto por 400 artículos contenidos en siete libros, derogó el código promulgado en 1957-1958 y modificado en septiembre de 1993. Ha sido modificado por la ley 08-09 de 16 de julio de 2010, véase Mudawwanat al-Usra. s.l.: Wizārat al-'Adl wa-1-Hurriyyāt, 2010, pp. 66-71, y para la traducción RUIZ-ALMODÓVAR, Caridad, El derecho privado en los países árabes, pp. 272-276.

${ }^{14}$ Promulgado por la ley 052 de junio de 2001, está compuesto de 313 artículos contenidos en cuatro libros, véase Mudawwanat al-ahwāl al-šajșiyya. Nuakchott: Kitābat al-Dawla li-l-Šu'ūn al-Mar'a, 2001, pp. 12-13, y para la traducción RUIZ-ALMODÓVAR, Caridad, El derecho privado en los países árabes, pp. 322-326.

${ }^{15}$ Promulgado el 22 de febrero de 2006, este código está compuesto por 301 artículos contenidos en

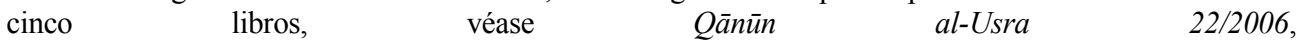
http://www.gcc-legal.org/MojPortalPublic/LawAsPDF.aspx?opt\&country=3\&LawID=2978 (consultada 29-03-2008), arts. 191-240, y para la traducción RUIZ-ALMODÓVAR, Caridad, "El Código Qatarí de la Familia”, Miscelánea de Estudios Árabes y Hebraicos, Sección Árabe-Islam, 58 (2009), pp. 274-279.

${ }^{16}$ Arts. 184 argelino; 1 egipcio; 240 emiratí; 64 iraquí; 254 jordano; 213 kuwaití; 277 marroquí; 203 mauritano; 198 omaní; 206 qatarí; 207 sirio; 286 sudanés; 171 tunecino; 227 yemení.

${ }^{17}$ Arts. 185 argelino; 12 egipcio; 243 emiratí; 70 iraquí; 274/b jordano; 224 kuwaití; 277 marroquí; 203 mauritano; 200 omaní; 208 qatarí; 218 sirio; 287 sudanés; 179 tunecino; 236 yemení.
} 
las disposiciones testamentarias hay que deducir las cargas que soporta el caudal hereditario, así como los gastos del entierro del testador.

\section{CONCLUSIÓN DEL TESTAMENTO}

El testamento se concluye ${ }^{18}$ oralmente, por escrito o por signos inteligibles cuando el testador sea incapaz de realizarlo de cualquiera de las otras dos formas y se puede aplazar, subordinar o limitar a una condición ${ }^{19}$ siempre que ésta sea válida

La condición válida es aquella que sea compatible con los objetivos legales, tenga interés para el testador, el legatario $\mathrm{u}$ otra persona y no transgreda ni contradiga el sentido de la ley, teniéndose que cumplir siempre que el interés propuesto por ella sea cierto o probable.

En caso de que el testamento incluya una condición no válida, dicho testamento será válido y la condición se revocará, pero si depende para su ejecución de una condición no válida, dicho testamento será nulo.

\section{ELEMENTOS CONSTITUTIVOS Y REQUISITOS DEL TESTAMENTO}

Aquello cuyo cumplimiento es necesario para su validez. Los elementos constitutivos son los cuatro componentes del testamento, a saber: el texto, el testador, el legatario y el legado. En cuanto a los requisitos son todas aquellas condiciones que se tienen que cumplir para que el testamento sea válido.

El incumplimiento de alguno de los elementos constitutivos o de los requisitos convierte al testamento en nulo ${ }^{20}$.

\subsection{EL TEXTO}

Es el testamento en sí y para su validez se requiere que no contenga contradicciones, ambigüedades ni nada prohibido legalmente ${ }^{21} \mathrm{y}$ que esté recogido en un documento oficial notarial o en un escrito redactado, fechado y firmado por el testador, en caso de no saber escribir, con su sello o la huella de su pulgar ${ }^{22}$.

Cuando no exista prueba escrita del testamento se podrá autentificar dicho testamento oralmente por el testimonio de dos testigos.

Además el código iraquí (art. 65/1) añade la obligatoriedad de que lo ratifique un secretario notario cuando el legado exceda de quinientos dinares, tanto sea de bienes inmuebles como de bienes muebles.

${ }^{18}$ Arts. 2 egipcio; 246 emiratí; 256 jordano; 214 kuwaití; 295 marroquí; 205 mauritano; 203 omaní; 213 qatarí; 208 sirio; 290 sudanés; 229 yemení.

${ }^{19}$ Arts. 199 argelino; 4 egipcio; 241-242 emiratí; 267 jordano; 216 kuwaití; 285 marroquí; 211 mauritano; 199 omaní; 207 qatarí; 210 sirio; 291 sudanés; 172 tunecino.

${ }^{20}$ Arts. 201 argelino; 14-16 egipcio; 270 emiratí; 72 iraquí; 226 kuwaití; 314 marroquí; 230 mauritano; 228 omaní; 238 qatarí; 220 sirio; 317 sudanés; 197 tunecino; 233 yemení.

${ }^{21}$ Arts. 3 egipcio; 278 jordano; 215 kuwaití; 278 marroquí; 204 mauritano; 209 sirio; 229 yemení.

${ }^{22}$ Arts. 191 argelino; 2 egipcio; 247 emiratí; 65 iraquí; 214 kuwaití; 296 marroquí; 205 mauritano; 204 omaní; 240 qatarí; 292 sudanés; 176 tunecino; 229 yemení. 


\subsection{EL TESTADOR (MUWAȘĪ)}

Es la persona ${ }^{23}$ que hace el testamento y estará facultado para ello siempre que esté capacitado para donar y no haya sido incapacitado.

En cuanto a la edad en que la persona está capacitada se establece en algunos códigos, así en el argelino es a los diecinueve años; en el egipcio y kuwaití a los dieciocho años con autorización del tutor; en el jordano y marroquí la mayoría de edad; en el código mauritano el menor capaz de discernir; en el tunecino a los dieciséis años con autorización del tutor y en el yemení la pubertad.

Con respecto al incapacitado, excepto los códigos omaní y yemení que no indican nada, el marroquí es el único que especifica que no considera válido el testamento del demente, del pródigo y del enajenado mientras no se cure o se le levante la incapacitación, en cambio en los demás códigos se excluye al que haya sido declarado incapaz por prodigalidad o por negligencia cuyo testamento será válido con la autorización del juez, excepto en el mauritano, qatarí y sudanés que lo será siempre ya que no establecen esta salvedad, aunque sólo podrá testar a favor de instituciones benéficas, igual le ocurre al menor dotado de discernimiento en el código mauritano.

Existen otras condiciones que únicamente recogen algunos códigos, así en el egipcio (art. 3), kuwaití (art. 215) y mauritano (art. 206) se especifica que cuando el testador sea un no-musulmán su testamento será válido, en los dos primeros, siempre que no esté prohibido por su ley ni por la ley islámica y en el tercero sin indicar nada más; en el emiratí (art. 270/6), kuwaití (art. 217/d) y qatarí (art. 238/ 6), se aclara que el testador no sea apóstata y en caso de que lo fuese su testamento, únicamente, sería válido tras su vuelta al Islam y en el yemení (art. 230/b), se requiere que el testador no esté endeudado por una cantidad superior a sus bienes.

Finalmente el testador, en todo momento y sea cual sea su estado físico, puede modificar, introducir condiciones o revocar, explícita o implícitamente, su testamento, total o parcialmente ${ }^{24}$.

Se considera revocación todo hecho o disposición que implique, por evidencia o costumbre, su anulación mientras que el testador no declare su intención de no revocarlo, tal como la disposición, venta o pérdida por parte del testador de los bienes específicos de los que hizo testamento ${ }^{25}$.

Por el contrario no se considera revocación otros hechos, tales como la hipoteca de los bienes legados, la eliminación de su estructura, el cambio del nombre del legado o de la mayor parte de sus características, ni que se añada algo cuya entrega no

${ }^{23}$ Arts. 186 argelino; 5 egipcio; 248/1-2 emiratí; 67 iraquí; 269 jordano; 217 kuwaití; 279 marroquí; 206 mauritano; 205/a omaní; 214 qatarí; 211 sirio; 293 sudanés; 178 tunecino; 230 yemení.

${ }^{24}$ Arts. 192 argelino; 18 egipcio; 248/3 emiratí; 72/1 iraquí; 258 jordano; 228 kuwaití; 286 marroquí; 212 mauritano; 205/b omaní; 237 qatarí; 220/d sirio; 294/1 sudanés; 177 tunecino; 257 yemení.

${ }^{25}$ Arts. 192 argelino; 18 egipcio; 248/4 emiratí; 72/1 iraquí; 228 kuwaití; 287 marroquí; 212 mauritano; 205/c omaní; 237 qatarí; 221 sirio; 294/2 sudanés; 257 yemení. 
sea posible excepto con dicho legado, a menos que la evidencia o costumbre indiquen que el testador se proponía con ello la revocación del testamento ${ }^{26}$.

\subsection{EL LEGATARIO (MŪṢÀ LA-HU)}

Es el beneficiario del testamento y puede ser una o varias personas concretas o sin definir, asociaciones, instituciones benéficas, lugares de culto o fundaciones de utilidad pública. De manera general se le requiere que sea conocido y exista, real o hipotéticamente, en el momento de la redacción del testamento y del fallecimiento del testador ${ }^{27}$; que no sea una institución ilícita ${ }^{28}$; que no sea heredero del testador ${ }^{29}$, excepto que lo permitan los demás herederos después del fallecimiento del testador; $\mathrm{y}$, finalmente, que no sea el asesino o el causante de la muerte del testador ${ }^{30}$.

La mayoría de los códigos especifican que el legatario puede ser de diferente religión $^{31} \mathrm{y}$ de distinta nacionalidad ${ }^{32}$ que el testador, pero, en este caso, se requiere la reciprocidad, es decir, que la ley del país del legatario permita el legado al natural de otra nación. En el código iraquí, en caso de que el legatario sea no-musulmán o extranjero, será válido el legado de los bienes muebles, únicamente.

Cuando el legatario sea un no nato, se requiere que nazca vivo ${ }^{33} \mathrm{y}$ que dicho nacimiento tenga lugar en el plazo máximo determinado para el embarazo a contar desde el momento de establecerse el testamento, excepto en los códigos argelino y marroquí, que no indican nada y, en el yemení, que dicho plazo es de seis meses. En este caso, los beneficios del legado se separarán hasta que el no nato se haga cargo de ellos.

Algunos códigos aclaran que en caso de embarazo múltiple ${ }^{34}$, todos ellos se repartirán lo correspondiente al no nato sin distinción de sexos, a menos que en el testamento se haga constar lo contrario, aunque nazcan con una diferencia entre ellos de seis meses como máximo, pero si alguno de ellos nace muerto, el sobreviviente tendrá derecho a todo el legado, por el contrario si alguno de ellos fallece después del nacimiento, su parte se repartirá entre sus herederos cuando el legado sea de bienes específicos y entre los herederos del testador cuando el legado sea de usufructos.

${ }^{26}$ Arts. 193 argelino; 19 egipcio; 229 kuwaití; 237 qatarí; 222 sirio; 257 yemení.

${ }^{27}$ Arts. 187 argelino; 6 egipcio; 251 emiratí; 68/1 iraquí; 270-271 jordano; 218 kuwaití; 281-282 marroquí; 207 mauritano; 208 omaní; 215 qatarí; 212 sirio; 295/a-b sudanés; 184 tunecino; 231/b-c yemení.

${ }^{28}$ Arts. 295/c sudanés; 231/a yemení.

${ }^{29}$ Arts. 189 argelino; 250 emiratí; 274/c jordano; 280 y 283/1 marroquí; 203 mauritano; 207 omaní; 208 qatarí; 297/1 sudanés; 179 tunecino; 231/d y 234 yemení.

${ }^{30}$ Arts. 188 argelino; 17 egipcio; 270/4 emiratí; 68/2 iraquí; 273 jordano; 227 kuwaití; 283/2 marroquí; 230/5 mauritano; 228/5 omaní; 238/4 qatarí; 223 sirio; 295/d y 317/f sudanés; 198 tunecino; 231/e y 233/7 yemení.

${ }^{31}$ Arts. 200 argelino; 9 egipcio; 249 emiratí; 71 iraquí; 274/a jordano; 221 kuwaití; 206 omaní; 216 qatarí; 215/1 sirio; 296 sudanés; 174 tunecino; 240 yemení.

${ }^{32}$ Arts. 9 egipcio; 71 iraquí; 274/a jordano; 221 kuwaití; 206 omaní; 215/2 sirio; 296 sudanés; 175 tunecino.

${ }^{33}$ Arts. 187 argelino; 35 egipcio; 276/a jordano; 245 kuwaití; 304 marroquí; 222 y 225 mauritano; 236 sirio; 184 tunecino; 239 yemení.

${ }^{34}$ Arts. 187 argelino; 36 egipcio; 254/4 emiratí; 276/c jordano; 246 kuwaití; 213/d omaní; 221 qatarí; 237 sirio. 
El legatario será propietario del legado desde el momento del fallecimiento del testador mientras que en el testamento no conste otra $\operatorname{cosa}^{35}$. Pero para ello, siempre que sea una persona o entidad determinada, tiene que aceptar o rechazar ${ }^{36}$ el legado en el plazo máximo de un mes desde la notificación del testamento; en el tunecino este período es de dos meses y en el argelino, marroquí, mauritano y yemení no se indica tiempo alguno. El silencio del legatario durante dicho plazo, en unos códigos $^{37}$, se considera aceptación, en cambio en otro ${ }^{38}$, su mutismo se entiende como rechazo.

Los códigos marroquí, mauritano y sirio no recogen expresamente la obligación de que exista aceptación, pero se deduce del articulado y, sobre todo, al establecer, al igual que otros códigos, en un misma redacción "El legado a favor de una persona indeterminada no necesita ser aceptado ni rechazado por nadie" ${ }^{39}$. Los códigos egipcio (art. 6/2), kuwaití (art. 218/b) y qatarí (art. 215/3) inciden aún más en ello cuando no requieren que el legatario indeterminado exista en el momento del testamento ni del fallecimiento del testador.

La aceptación o el rechazo lo tiene que realizar el propio legatario si es mayor de edad y está capacitado. En el caso de que sea un no nato, un menor o un incapacitado, su aceptación o su rechazo le corresponderá a quien tenga la tutela de sus bienes ${ }^{40}, \mathrm{y}$, finalmente, si el legatario es una asociación, institución benéfica, lugar de culto o fundación de utilidad pública, su aceptación o su rechazo será por parte de quien les representen legalmente y si no tienen representante, el legado será obligatorio ${ }^{41}$.

En caso de que el legatario fallezca antes de aceptar o rechazar el legado, se trasladará este derecho a sus herederos ${ }^{42}$.

Tanto la aceptación como el rechazo puede ser total o parcial ${ }^{43}$, por ello si el legatario acepta una parte del legado y rechaza otra parte, el testamento se ejecutará en lo que haya sido aceptado y se anulará en lo que haya sido rechazado. De igual modo si existen varios legatarios y algunos de ellos aceptan y los otros rechazan, únicamente, se ejecutará en relación a lo aceptado y a quienes acepten y se anulará en relación a lo rechazado y a quienes rechacen.

${ }^{35}$ Arts. 25 egipcio; 256/1 emiratí; 265/a jordano; 235 kuwaití; 213/a omaní; 221 qatarí; 302/1 sudanés.

${ }^{36}$ Arts. 197 argelino; 20 y 22 egipcio; 252/1, 253 y 254 emiratí; 257 y 261/b jordano; 230 y 232 kuwaití; 289 marroquí; 214 mauritano; 209/a y 211 omaní; 217-219 qatarí; 226 y 227 sirio; 298/1, 299 y 300 sudanés; 194 tunecino; 258 yemení.

${ }^{37}$ Arts. 253/2 emiratí; 210/b omaní; 218 qatarí; 227/2 sirio; 299/3 sudanés; 194 tunecino.

${ }^{38}$ Arts. 22 egipcio; 232 kuwaití; 258 yemení.

${ }^{39}$ Arts. 253/2 emiratí; 288 marroquí; 213 mauritano; 209/c omaní; 217 qatarí; 225 sirio; 298/3 sudanés.

${ }^{40}$ Arts. 20 egipcio; 252/3 emiratí; 259 jordano; 230 kuwaití; 209/b omaní; 217 qatarí; 298/2 sudanés; 258 yemení.

${ }^{41}$ Arts. 20 egipcio; 252/4 emiratí; 230 kuwaití; 209/d omaní; 217 qatarí; 298/4 sudanés.

${ }^{42}$ Arts. 198 argelino; 21 egipcio; 255 emiratí; 263 jordano; 231 kuwaití; 289 marroquí; 214 mauritano; 212 omaní; 220 qatarí; 301 sudanés; 194 tunecino.

${ }^{43}$ Arts. 23 egipcio; 254 emiratí; 262 jordano; 233 kuwaití; 291 marroquí; 215 mauritano; 211 omaní; 219 qatarí; 228 sirio; 300 sudanés; 195 tunecino. 
Finalmente la aceptación, explícita o implícitamente, del legado se tiene que realizar después del fallecimiento del testador, pero, en caso de que tuviera lugar antes, se requiere que persista en ello después. Por el contrario en el rechazo, únicamente, tendrá valor legal aquél que se realice tras el fallecimiento del testador y antes de la aceptación $^{44}$, no siendo válido el rechazo después de haber aceptado, ni la aceptación después de haber rechazado, excepto que los herederos lo permitan ${ }^{45}$.

\subsection{EL LEGADO (MŪṢÀ BI-HI)}

Es aquello de lo que se hace testamento y para su validez se requiere ${ }^{46}$ que sea un bien específico, usufructo o rentas, que exista y sea propiedad del testador en el momento del fallecimiento, y que no exceda el límite del tercio disponible del caudal hereditario si el testador tiene herederos.

El objeto ${ }^{47}$ del legado podrá ser un bien específico inmueble o mueble, fungible o no fungible, en especie o usufructo, a perpetuidad o por un plazo determinado o sin determinar, en este último caso se considera vitalicio y finalizará con el fallecimiento del legatario.

Cuando el legado sea a favor de Dios el Altísimo y de obras benéficas sin determinar su destino, éste se tiene que emplear en obras de caridad ${ }^{48}$; cuando sea a favor de una determinada asociación, institución benéfica, lugar de culto o fundación de utilidad pública, se utilizará en su mantenimiento y asuntos ${ }^{49}, \mathrm{y}$, finalmente, cuando sea a favor de una asociación, institución benéfica, lugar de culto o fundación aún sin crear y su creación sea imposible, el legado se dedicará al fin que le sea más similar ${ }^{50}$, excepto en los códigos egipcio (art. 8) y jordano (art. 275/c) en que dicho legado será nulo.

Finalmente en algunos códigos ${ }^{51}$ se establece que el legado se repartirá por igual entre los legatarios cuando en el testamento se adjudique una cosa a una persona y luego a otra, excepto que se pruebe o se indique que el propósito de ello era eliminar el primer legado. Por el contrario en los otros $\operatorname{códigos}^{52}$ se indica que si el legado se atribuye a otro el primer legatario no tendrá derecho a nada y si se atribuye a otro sólo una parte tendrá derecho únicamente a lo que quede.

${ }^{44}$ Arts. 24 egipcio; 253/1 emiratí; 234/a-b kuwaití; 290 marroquí; 214 mauritano; 210/a omaní; 217 qatarí; 227/1 sirio; 299/1 sudanés.

${ }^{45}$ Arts. 24 egipcio; 264 jordano; 234/c kuwaití; 229 sirio; 196 tunecino.

${ }^{46}$ Arts. 190 argelino; 10 egipcio; 261 emiratí; 69 iraquí; 277 jordano; 222 kuwaití; 292 marroquí; 208 mauritano; 220 omaní; 228 qatarí; 216 sirio; 309 sudanés; 186 tunecino; 232 yemení.

${ }^{47}$ Arts. 196 argelino; 294 marroquí; 221-223 omaní; 231 qatarí; 310-313 sudanés.

${ }^{48}$ Arts. 7 egipcio; 275/b jordano; 219/a kuwaití; 308 marroquí; 226 mauritano; 213/1 sirio.

${ }^{49}$ Arts. 7 egipcio; 275/a jordano; 219/b kuwaití; 309 marroquí; 219 omaní; 227 qatarí; $213 / 2$ sirio; 308/1 sudanés; 173 tunecino.

${ }^{50}$ Arts. 220 kuwaití; 310 marroquí; 226 mauritano; 214 sirio; 308/2 sudanés.

${ }^{51}$ Arts. 194 argelino; 224 mauritano; 222/b omaní; 232 qatarí; 311/2 sudanés; 256 yemení.

${ }^{52}$ Arts. 47-49 egipcio; 257-259 kuwaití; 306 marroquí; 243-245 sirio; 185 tunecino. 